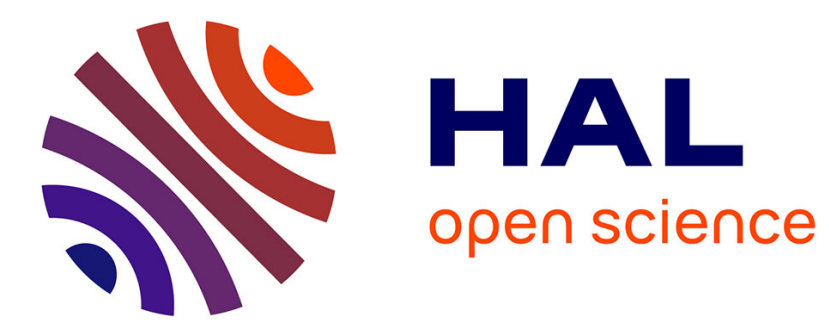

\title{
The monsoon aerosol extinction properties at Goa during INDOEX as measured with lidar \\ Patrick Chazette
}

\section{To cite this version:}

Patrick Chazette. The monsoon aerosol extinction properties at Goa during INDOEX as measured with lidar. Journal of Geophysical Research, 2003, 108 (D6), 10.1029/2002JD002074 . hal-02902698

\section{HAL Id: hal-02902698 \\ https://hal.science/hal-02902698}

Submitted on 20 Mar 2021

HAL is a multi-disciplinary open access archive for the deposit and dissemination of scientific research documents, whether they are published or not. The documents may come from teaching and research institutions in France or abroad, or from public or private research centers.
L'archive ouverte pluridisciplinaire HAL, est destinée au dépôt et à la diffusion de documents scientifiques de niveau recherche, publiés ou non, émanant des établissements d'enseignement et de recherche français ou étrangers, des laboratoires publics ou privés. 


\title{
The monsoon aerosol extinction properties at Goa during INDOEX as measured with lidar
}

\author{
Patrick Chazette \\ Laboratoire des Sciences du Climat et de l'Environnement, UMR 1572 CEA-CNRS, Gif-sur-Yvette, France
}

Received 9 January 2002; revised 25 March 2002; accepted 8 April 2002; published 27 March 2003.

[1] The aerosol extinction properties in the framework of the Indian Ocean Experiment (INDOEX) are documented over the Goa area (western coast of India, $15.45^{\circ} \mathrm{N}, 73.08^{\circ} \mathrm{E}$ ) between 1 and 15 March 1999. The temporal evolution and the vertical distribution of the aerosol trapped inside the winter monsoon plume have been studied using a groundbased lidar system (micropulse lidar (MPL) emitting at $523 \mathrm{~nm}$ ). Both the vertical structure and the optical properties of the particles have been assessed from the inversion of the lidar signals. A statistical approach has been used to determine the backscatter-toextinction ratio $\left(\Phi_{p}\right)$, a key parameter to invert the lidar signal. Sun photometer-retrieved optical thickness at $523 \mathrm{~nm}$ is used to constrain the inversion in daytime and leads to a mean value of $\Phi_{p}$ close to $0.03 \mathrm{sr}^{-1}$ with a standard deviation of $\sim 0.010 \mathrm{sr}^{-1}$. Black carbon concentration $(B C)$ is shown to be a representative tracer of the surface scattering coefficient of aerosols $\left(\alpha_{s}\right)$, the relative humidity $(R H)$ effect seeming to be of a second order. A statistical linear relationship between $B C$ and $\alpha_{s}$ has been found and then used to constrain the lidar inversion during nighttime. During nighttime, about the same mean $\Phi_{p}$ has been assessed. The lidar-derived optical thickness is shown to be more important during nighttime over the entire measurement period (a mean value of $0.76 \pm 0.15$ for nighttime instead of $0.55 \pm 0.09$ for daytime). A significant contribution to the optical thickness is shown to be due to an aerosol layer within $0.7 \mathrm{~km}$ above sea level (ASL). A second aerosol layer is found between 0.7 and $\approx 3.5 \mathrm{~km}$ ASL with an important diurnal variability in both its altitude extension and its optical thickness. Such a variability seems to be due to the sea breeze cycle. In the upper aerosol layer, optical thickness is $0.49 \pm$ 0.14 during nighttime whereas it is only about $0.25 \pm 0.07$ during daytime. INDEX TERMS: 0305 Atmospheric Composition and Structure: Aerosols and particles $(0345,4801) ; 0345$ Atmospheric Composition and Structure: Pollution - urban and regional (0305); 0365 Atmospheric Composition and Structure: Troposphere - composition and chemistry; 0394 Atmospheric Composition and Structure: Instruments and techniques

Citation: Chazette, P., The monsoon aerosol extinction properties at Goa during INDOEX as measured with lidar, J. Geophys. Res., 108(D6), 4187, doi:10.1029/2002JD002074, 2003.

\section{Introduction}

[2] The main field experiment of the Indian Ocean Experiment (INDOEX) was held during the 1999 winter monsoon. Numerous platforms were used to quantify the aerosol role on the Earth to atmospheric system [Ramanathan et al., 1995, webmanager@fiji.ucsd.edu]. The aerosol composition, stratification and transport have been quantified [i.e., Ramanathan et al., 2001; Rash et al., 2001; Léon et al., 2001]. The aerosol inside the monsoon plume is mainly from anthropogenic origin and thus consists of sulfates, soot and organic carbon [i.e., Satheesh et al., 1999; Ramanathan et al., 2001]. Indeed, local fossil fuel and agricultural biomass burning cause a high aerosol loading over the Indian Ocean [Lelieveld et al., 2001]. Mineral dusts from wind erosion of local soils or remote

Copyright 2003 by the American Geophysical Union. 0148-0227/03/2002JD002074 deserts contribute to this aerosol load [Satheesh et al., 1999; Ramanathan et al., 2001; Léon et al., 2001].

[3] Such atmospheric aerosols have a significant impact on the Earth radiative budget [i.e., Charlson et al., 1992, 1999] and on atmospheric chemistry through the modification of the photolitic rates [i.e., Dickerson et al., 1997]. A reliable quantification of these impacts is conditioned by the knowledge of the emission and transport processes. Such processes can be constrained by the measurements of both the structural and the optical properties of the aerosols in the atmospheric column. For instance, the temporal evolution of the aerosol optical thickness is one of the most important parameters to both validate and constrain the aerosol transport model [Rash et al., 2001].

[4] Lidar is the only instrument that can efficiently and continuously measure the vertical distribution of the aerosols into the atmosphere [i.e., Measures, 1984] with a high vertical resolution $(\approx 15 \mathrm{~m})$. Lidar was used on various sites during the INDOEX Intensive Field Phase (IFP) from 


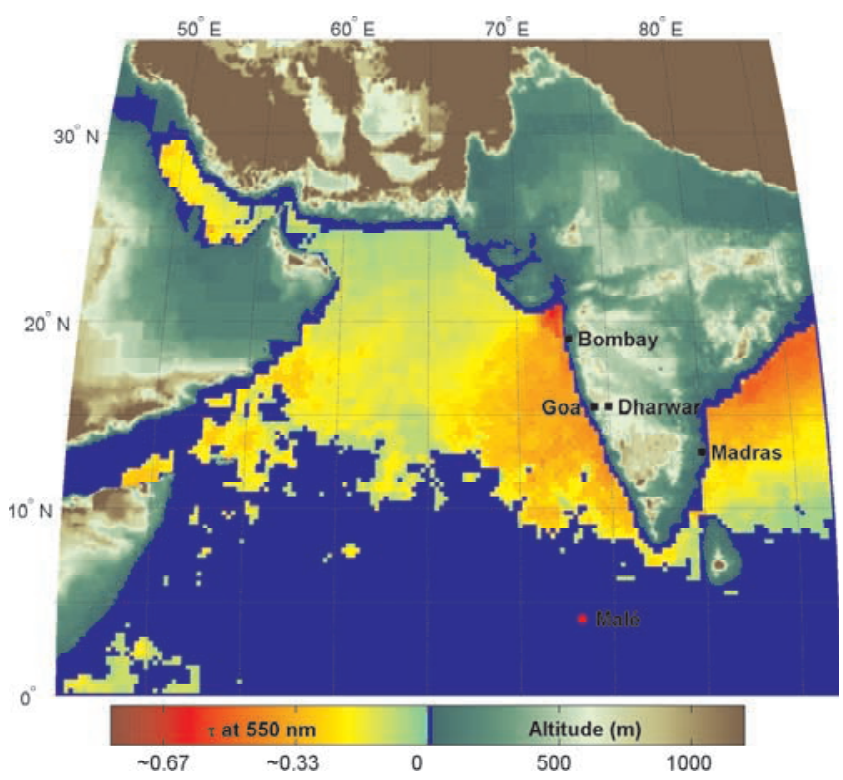

Figure 1. Location of the instrumental site of Goa $\left(15.45^{\circ} \mathrm{N}, 73.08^{\circ} \mathrm{E}\right)$. The red to light-green color palette gives the Meteosat-retrieved optical thickness $\tau$ at $550 \mathrm{~nm}$ over sea (1-15 March average; no significant data are available for purple areas). The green to brown color palette gives the altitude over land.

January to March 1999. A six-wavelength aerosol lidar was used at Maldives (Hulule island, $4.1^{\circ} \mathrm{N}, 73.3^{\circ} \mathrm{E}$ ) [Ansmann et al., 2000], a two-wavelength backscatter aerosol lidar was used onboard aircraft [Chazette et al., 2000; Pelon et al., 2001] and a one-wavelength micropulse lidar (MPL) [Spinhirne, 1993] was used on the coastal site of Goa $\left(15.45^{\circ} \mathrm{N}\right.$, $\left.73.08^{\circ} \mathrm{E}\right)$ of the Indian subcontinent [Sicard et al., 2002].

[5] Various methods have been developed to invert the lidar measurements in order to retrieve the vertical profile of the extinction coefficient of the aerosols. Multiwavelength or multiangular inversion methods can be used to retrieve this parameter as respectively shown by Ansmann et al. [2000] and Sicard et al. [2002]. A more common method is to use Bernoulli's differential form of the propagation equation [i.e., Fernald et al., 1972; Kohl, 1978; Klett, 1981]. The stable analytical form of the solution is underconstrained. It is expressed as a function of 2 unknown parameters at each altitude range: the backscatter-to-extinction ratio $\left(\Phi_{p}\right)$ and the boundary condition at the far end of the inversion range. The boundary condition is more easily determined by considering the upper part of the lidar profile where the scattering is due only to the atmospheric molecule (Rayleigh scattering). $\Phi_{p}$ depends on the aerosol model via the size distribution, the complex refractive index and the particle shapes. Often it is not possible to directly determine $\Phi_{p}$ and it is necessary to know both the aerosol origin and the processes of transport to fix an aerosol model. Such assessments have been conducted in some case studies, mainly for the dust aerosols [Hamonou et al., 1999; Chazette et al., 2001] or marine aerosols [Flamant et al., 1998]. If external constraints can be used, such as the aerosol optical thickness, it is then possible to retrieve both the extinction profile and an equivalent $\Phi_{p}$ for the atmospheric column [Pelon et al., 2001]. This value of $\Phi_{p}$ is more representative of the altitude ranges that contribute significantly to the aerosol extinction coefficient.

[6] This paper aims at determining the diurnal evolution of the aerosol optical properties inside the winter monsoon layer observed at Goa during INDOEX IFP. The assessment of the equivalent $\Phi_{p}$ on the atmospheric column is performed for daytime and nighttime, using data from the MPL installed on the Goa site between 1 and 15 March 1999 [Léon et al., 2001]. Inversion procedures have been developed based on the previous studies quoted. The inversion procedures are based on statistical analyses that enable to limit the ambiguities linked to a noisy signal. The optical properties of the monsoon layer and their temporal evolutions are tentatively discussed in light of the air mass origins.

\section{Instrumental Site of Goa}

\subsection{Geographical Position}

[7] The Goa experimental site $\left(15.45^{\circ} \mathrm{N}, 73.08^{\circ} \mathrm{E}\right)$ has been selected because of its geographical position, bounded on its western side by the Arabian Sea and by the Western Ghats on its eastern side. In Figure 1, the left color palette (from red to light green) gives the mean value over ocean of the optical thickness at $550 \mathrm{~nm}$ retrieved from Meteosat 5 measurements [Léon et al., 2001] between 1 and 15 March. Aerosol plumes are highlighted over both the Indian Ocean and the Bay of Bengal. A high aerosol load is observed off Goa. The right color palette (from green to brown), gives the altitude over land. The Western Ghats are a $700 \mathrm{~m}$ high mountain ridge parallel to the seashore and located $50 \mathrm{~km}$ from the Goa instrumental site. The station was set up at the Goa University campus near the coast, south of Panaji. The site altitude is close to $20 \mathrm{~m}$ above sea level (ASL).

\begin{tabular}{|c|c|c|c|c|c|c|c|c|c|c|c|c|c|c|c|c|}
\cline { 2 - 10 } \multicolumn{1}{c|}{} & \multicolumn{10}{c|}{ March 1999 } \\
\cline { 2 - 11 } \multicolumn{1}{c|}{} & $\mathbf{1}$ & $\mathbf{2}$ & $\mathbf{3}$ & $\mathbf{4}$ & $\mathbf{5}$ & $\mathbf{6}$ & $\mathbf{7}$ & $\mathbf{8}$ & $\mathbf{9}$ & $\mathbf{1 0}$ & $\mathbf{1 1}$ & $\mathbf{1 2}$ & $\mathbf{1 3}$ & $\mathbf{1 4}$ & $\mathbf{1 5}$ & $\rightarrow \mathbf{2 3}$ \\
\hline Lidar & & & & & & & & & & & & & & & & \\
\hline Sunphotometer & & & & & & & & & & & & & & & \\
\hline Nephelometer & & & & & & & & & & & & & & & \\
\hline Aethalometer & & & & & & & & & & & & & & & \\
\hline
\end{tabular}

Figure 2. Summary of the instrument operation periods (gray cells). 


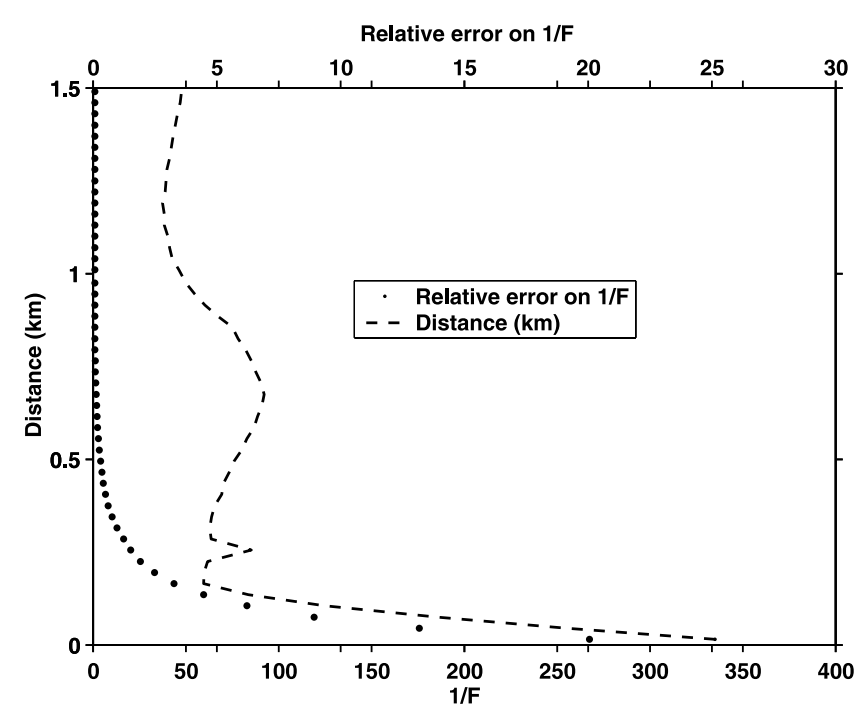

Figure 3. Inverse of the overlap function $F$ as a function of the distance from the laser source. The relative error in $1 / F$ is also given.

Measurements performed on this site enable to characterize the aerosol plume leaving the Indian subcontinent due to the northeasterly winter monsoon flow [Alfaro et al., 2001; Léon et al., 2001].

\subsection{Instrumental Design}

[8] Various instruments equipped the Goa site [Léon et al., 2001]. Only the four instruments used for this study are presented here: a MPL manufactured by Science and Engineering Services Inc., USA; a Sun photometer manufactured by CIMEL Electronic, France; a nephelometer manufactured by TSI, USA and an aethalometer AE-14 manufactured by Magee Scientific, USA. Figure 2 summarizes the instrument operation periods.

\subsubsection{Lidar}

[9] The design of the MPL used in this work is well described by Spinhirne et al. [1985] and it is also possible to visit the NASA MPL website at http://virl.gsfc.nasa.gov/ mpl.html. This instrument is now commercially available from Science and Engineering Services, Inc. (SESI) through a technology transfer license. The emitted wavelength is $\approx 523 \mathrm{~nm}$ with efficient output energy close to $4.5 \mu \mathrm{J}$. The laser frequency was set at $2 \mathrm{kHz}$ for all the measurements and lidar measurements integrated over $5 \mathrm{~min}$ have been recorded with a vertical resolution of $30 \mathrm{~m}$. The photon counting mode was applied. In absence of background radiation, the lidar signal uncertainty followed a Poisson law that is a function of the number of photons backscattered to the telescope [Measures, 1984]. The influence on the different sources of uncertainty on the lidar signal processing is discussed further in section 3 .

\subsubsection{Sun Photometer}

[10] The Sun photometer instrument performed measurements of the optical thickness at several wavelengths in the visible spectrum and the Angström coefficient $a$ was assessed in the same spectral region. For this study, the channels used are centered at 440 and $670 \mathrm{~nm}$, with bandwidths of less than $20 \mathrm{~nm}$. The instrument field of view is about $1^{\circ}$.
[11] The aerosol optical thickness at the lidar wavelength of $523 \mathrm{~nm}(\tau)$ was derived from the measurements in the blue $\left(\tau_{440}\right)$ and red channels $\left(\tau_{670}\right)$ by using the Angström relation [Angström, 1964]:

$$
\tau=\tau_{440}\left(\frac{523}{440}\right)^{-a} \text { where } a=^{L N\left(\tau_{670} / \tau_{440}\right)} / \operatorname{LN}\left(\frac{440}{670}\right)
$$

[12] The optical thickness obtained above the site comes from the AERONET website [Holben et al., 1998]. Typical relative uncertainties on the aerosol optical thickness at visible wavelengths are about $5 \%$ for an optical thickness close to 0.4 [Fouquart et al., 1987; Tanré et al., 1988]. The AERONET website gives a maximal absolute uncertainty of 0.02 that does not depend of aerosol loading.

[13] The relative uncertainty on $a$ ranges generally from $8 \%$ to $15 \%$ [Hamonou et al., 1999]. The resultant relative uncertainty on $\tau$ is less than $10 \%$ for the optical thickness range over Goa.

\subsubsection{Nephelometer}

[14] TSI nephelometer measured scattering coefficient in the scattering angle range $7-170^{\circ}\left(\alpha_{s}\right)$ and $90-170^{\circ}\left(\alpha_{b}\right)$ [Bodhaine et al., 1991] between 10 and 23 March 1999. The measurements were performed satisfyingly at two wavelengths: 450 and $700 \mathrm{~nm}$. The instrument was used in ambient relative humidity $(R H)$ without heating. Mean relative uncertainty linked to this instrument can be considered as less than $5 \%$. It is mainly due to residual heating that modifies the $R H$ inside the instrument. In dry conditions, the relative uncertainty after calibration is of the order of $1 \%$.

\subsubsection{Aethalometer}

[15] Black carbon concentration $(B C)$ was recorded continuously with the Aethalometer. The instrument, calibrated with a constant value of $19 \mathrm{~m}^{2} \mathrm{~g}^{-1}$, is sensitive to the lightabsorbent part of the aerosols [Hansen and Novakov, 1990]. This specific cross section is established for material trapped on the filter and is not valid for particles in the ambient atmosphere. An artificial enhancement of the absorption coefficient by a factor $\approx 2$ could be found due to multiple scattering into the filter fibers [Bodhaine, 1995]. In the following, the Aethalometer measurement is considered as a proxy of the $B C$ (other minor absorbents such as ferric oxides could be present). Relative uncertainty on the $B C$ measurements performed with this instrument is close to $10 \%$.

\section{Description of the Method}

\subsection{Basic Principle}

[16] The lidar equation gives the range-corrected signal $S(z)$ for the emitted wavelength of $\approx 523 \mathrm{~nm}$ as a function of the range $z$, the total backscatter $\beta(z)$ and extinction coefficients $\alpha(z)$ [Measures, 1984]:

$$
S(z)=C \cdot \beta(z) \cdot F(z) \cdot \exp \left[-2 \cdot \int_{z_{g}}^{z} \alpha\left(z^{\prime}\right) \cdot d z^{\prime}\right]
$$

where $z_{g}$ is the altitude ASL of the laser emission. $C$ is a constant that characterizes the lidar system and $F(z)$ is the overlap function. 


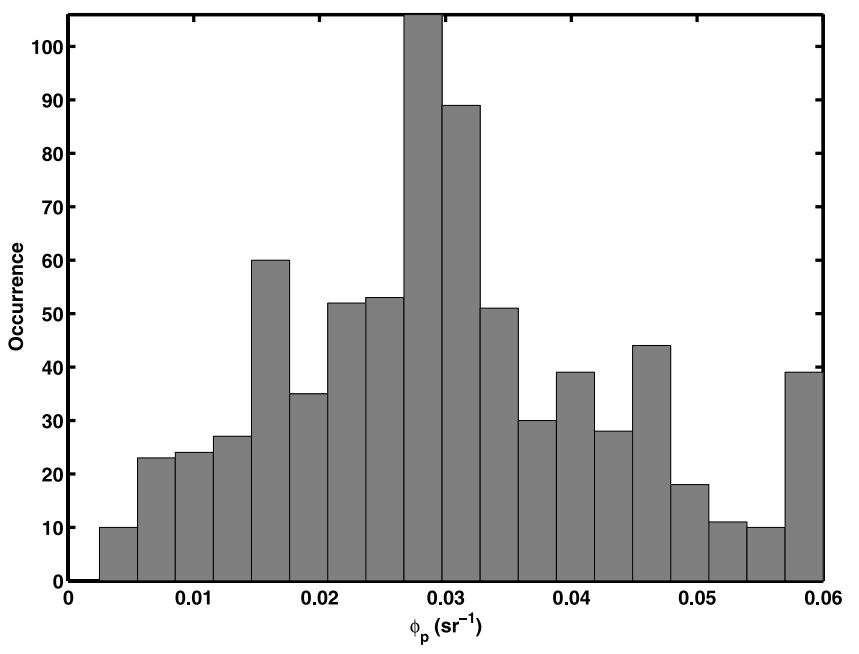

Figure 4. Histogram of the aerosol backscatter-to-extinction ratio $\left(\Phi_{p}\right)$ assessed from daytime lidar measurements.

[17] $S(z)$ is corrected from the background sky radiance, which is simultaneously measured with the lidar profile. The overlap function $F$ is a major source of uncertainty at low altitudes $(<0.5 \mathrm{~km})$ and the lidar signal must be corrected by the function $1 / F$. It has been measured in a horizontal layer in the atmosphere [Sicard et al., 2002]. Figure 3 gives the evolution of $1 / F$ as a function of the distance from the laser emission. The standard deviation of $1 / F$ is also shown. The lidar signal will be only considered as significant for a distance larger than $90 \mathrm{~m}$ (110 m ASL) that corresponds to a relative error smaller than $15 \%$ in $1 / F$.

[18] In the following, the lidar signal $S$ has been corrected by the multiplicative function $1 / F$. Klett [1985] gives the solution to the inverse problem for a stable backward procedure by

$$
\beta(z)=\frac{S(z) \cdot Q(z)}{\frac{S_{0}}{\beta_{0}}+2 \int_{z}^{z_{0}} \frac{1}{\Phi_{p}(z)} S\left(z^{\prime}\right) \cdot Q\left(z^{\prime}\right) \cdot d z^{\prime}}
$$

where $z_{0}$ is the reference altitude corresponding to the integration constant. $S_{0}$ and $\beta_{0}$ are respectively the signal and the backscatter coefficient at the altitude $z_{0} . Q(z)$ is the correction related to the differential molecular optical thickness calculated from the vertical profile of the molecular scattering coefficient $\alpha_{m}(z)$ :

$$
Q(z)=\exp \left(2 \cdot \int_{z}^{z_{0}}\left[\frac{\Phi_{m}}{\Phi_{p}(z)}-1\right] \cdot \alpha_{m}\left(z^{\prime}\right) \cdot d z^{\prime}\right)
$$

where $\Phi_{m}$ is the molecular normalized backscatter phase function $\left(3 / 8 \pi \mathrm{sr}^{-1}\right)$ and $\Phi_{p}(z)$ is the aerosol backscatter-toextinction ratio. The molecular contribution is derived from an ancillary climatic radiosounding database as in Chazette et al.'s [1995] study. The aerosol extinction coefficient $\alpha_{e}$, which is the sum of the scattering and absorbing coefficients, can then be obtained by

$$
\alpha_{e}(z)=\frac{1}{\Phi_{p}(z)}[\beta(z)-\underbrace{\Phi_{m} \alpha_{m}(z)}_{\beta_{m}(z)}]
$$

[19] The lidar-derived optical thickness $\left(\tau_{L}\right)$ is calculated as the integral of the extinction coefficient from the ground surface $\left(z_{g}\right)$ up to the reference altitude $\left(z_{0}\right)$ :

$$
\tau_{L}=\int_{z_{g}}^{z_{0}} \alpha_{e}(z) d z
$$

[20] The lidar equation is underconstrained since it is associated with three unknowns for each altitude: $\beta, \Phi_{p}$, and $\beta_{0}$. The reference value $\beta_{0}$ could be determined by considering the lidar signal where the molecular scattering is the major contributor to the total extinction (above the monsoon layer, for $z_{0}$ between 3.5 and $5 \mathrm{~km}$ height). To determine $\Phi_{p}$ it is necessary to consider an external constraint. In this way, the Sun photometer and the nephelometer measurements were used to constrain the lidar inversion.

[21] The Sun photometer provides the optical thickness on the integrated atmospheric column $(\tau)$ and the nephelometer part of the surface scattering coefficient $\left(\alpha_{s}\right)$. The optical thickness is mainly due to the contribution of both the local atmospheric boundary layer and the monsoon plume. With such constraints, it is possible to determine $\Phi_{p}$ with an iterative procedure if it does not vary with the altitude $\left(\Phi_{p}(z)=\Phi_{p}, \forall z\right)$. The procedure will be discussed hereafter for each situation that is considered (daytime and nighttime). Individual lidar profiles that are cloud-free have been selected by visual examination of quick-looks.

\subsection{Daytime Lidar Data Analysis}

[22] Lidar measurements performed during daytime are very noisy on the upper part of the profile. This is mainly due to the sky radiance. It is not possible to inverse the measurements on an individual profile basis. A statistical analysis is required.

[23] The Sun photometer derived optical thicknesses at $523 \mathrm{~nm}$ have been used as a constraint on the determination of $\alpha_{e}(z)$ through (6) as in the works of Welton et al. [2000], Flamant et al. [2000], or Pelon et al. [2001]. In terms of optical thickness, the part of the atmospheric column sounded by the lidar system is supposed to be representative of the entire atmospheric column. Such an assumption is possible because both the contribution of stratospheric aerosol is negligible and no other aerosol layer has been observed above $5 \mathrm{~km}$ ASL [i.e., Pelon et al., 2001]. Equivalent $\Phi_{p}$ on the atmospheric column has been assessed using an iterative procedure. Accounting for the uncertainties linked to $\tau$, the convergence is assumed when the lidarderived optical thickness $\left(\tau_{L}\right)$ is such as: $\left|\tau_{L}-\tau\right|<0.05$. This condition is linked to the absolute uncertainty on the optical thickness that can be retrieved from Sun photometer measurements (see section 2). The value of $\Phi_{p}$ is chosen in the large interval $[0.005 ; 0.060] \mathrm{sr}^{-1}$ that corresponds to the most probable values for the aerosols trapped inside the winter monsoon plume [Ansmann et al., 2000; Chazette et al., 2000; Pelon et al., 2001]. The initial value of $\Phi_{p}$ has been chosen to be $0.03 \mathrm{sr}^{-1}$ (the result is not dependant of this value) and the step for each iteration is $0.002 \mathrm{sr}^{-1} . \Phi_{p}$ is increased (decreased) if the lidar-derived optical thickness is lower (larger) than the Sun photometer-derived optical thickness.

[24] The statistical analysis has been conducted over 700 profiles acquired between 1 and 7 March and 9 and 


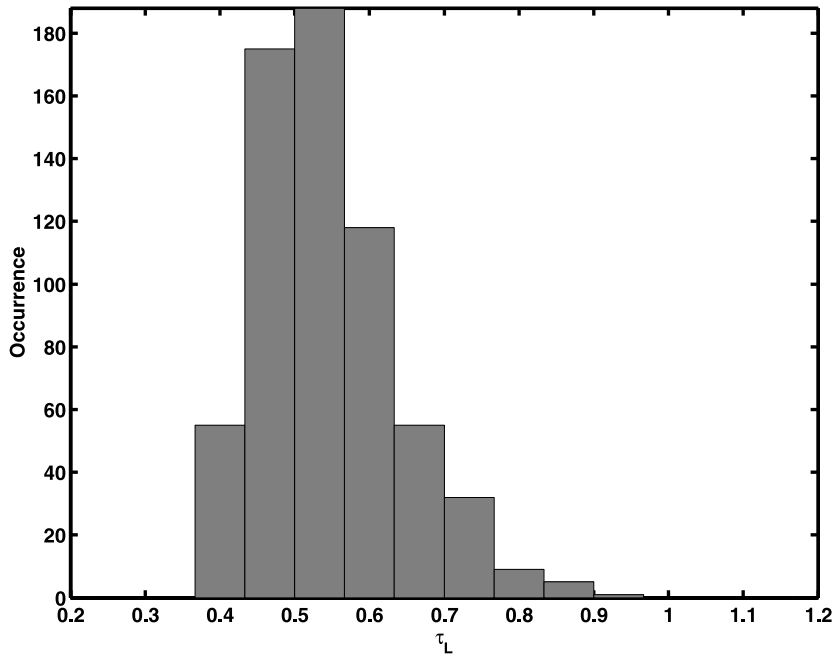

Figure 5. Histogram of the daytime lidar-retrieved aerosol optical thickness at $523 \mathrm{~nm}\left(\tau_{L}\right)$.

14 March 1999. The result is given in Figure 4. For 85\% of the profiles, the procedure has been convergent and the mean value calculated for the significant values of $\Phi_{p}$ is close to $0.028 \mathrm{sr}^{-1}$ with a standard deviation of $0.01 \mathrm{sr}^{-1}$.

[25] For the other profiles, where the iterative procedure has been non convergent, $\Phi_{p}$ has then been fixed as equal to $0.028 \mathrm{sr}^{-1}$. With such a value of $\Phi_{p}$ the lidar optical thickness retrieved in these cases is overestimated compared with the Sun photometer derived optical thickness. This may be due to a wrong value of the reference $S_{0}$. To check this last point, the reference $S_{0}$ has been assessed by a similar iterative procedure as for $\Phi_{p}$. Strong relative difference $(\approx 80 \%)$ has been established between the initial value of $S_{0}$ and the new fitted value. Such a discrepancy may be due to the presence of residual clouds at the top of the monsoon layer leading to a very weak signal-to-noise ratio (SNR) (smaller than 1) in the free troposphere.

[26] The histogram of the lidar optical thickness values retrieved during daytime is given in Figure 5. The mean value is equal to 0.55 with a standard deviation of 0.09 . No significant trend in $\tau_{L}$ has been observed over the entire lidar measurement period.

\subsection{Nighttime Lidar Data Analysis}

[27] Because the Sun photometer did not provide sensible data during nighttime nor on 8 and 15 March (Figure 2) the optical thickness cannot be used as a constraint for the lidar inversion scheme. Thus, the available ground in situ measurement could fortunately provide another constraint in the form of a boundary condition [Chazette et al., 1995].

\subsubsection{Use of the Ground In Situ Measurements}

[28] Simultaneous surface measurements of both $B C$ and $\alpha_{s}$ were performed during 17 days, between 10 and 26 March (Figure 2). The scatterplot of $B C$ as a function of $\alpha_{s}$ is given in Figure 6 for the nephelometer wavelengths of 450 and $700 \mathrm{~nm}$. The relationship is linear with a correlation coefficient close to $0.9: \alpha_{s}=0.03 B C+0.02$ and $\alpha_{s}=0.06 B C+0.02$ at 700 and $450 \mathrm{~nm}$, respectively. On the contrary no correlation is found between both the $B C$ and the $R H$, and between the Angström exponent $a$ and $R H$ (not shown).

[29] Thus, the aerosol close to the ground level seems to be weakly sensitive to $R H$. This can also be highlighted by the plot of the nephelometer backscatter-to-scattering ratio $R=\alpha_{b} / \alpha_{s}$ as a function of $R H$ given in Figure 7. For instance, if the monomodal aerosol model determined by Léon et al. [2001] from comparison between Meteosat and
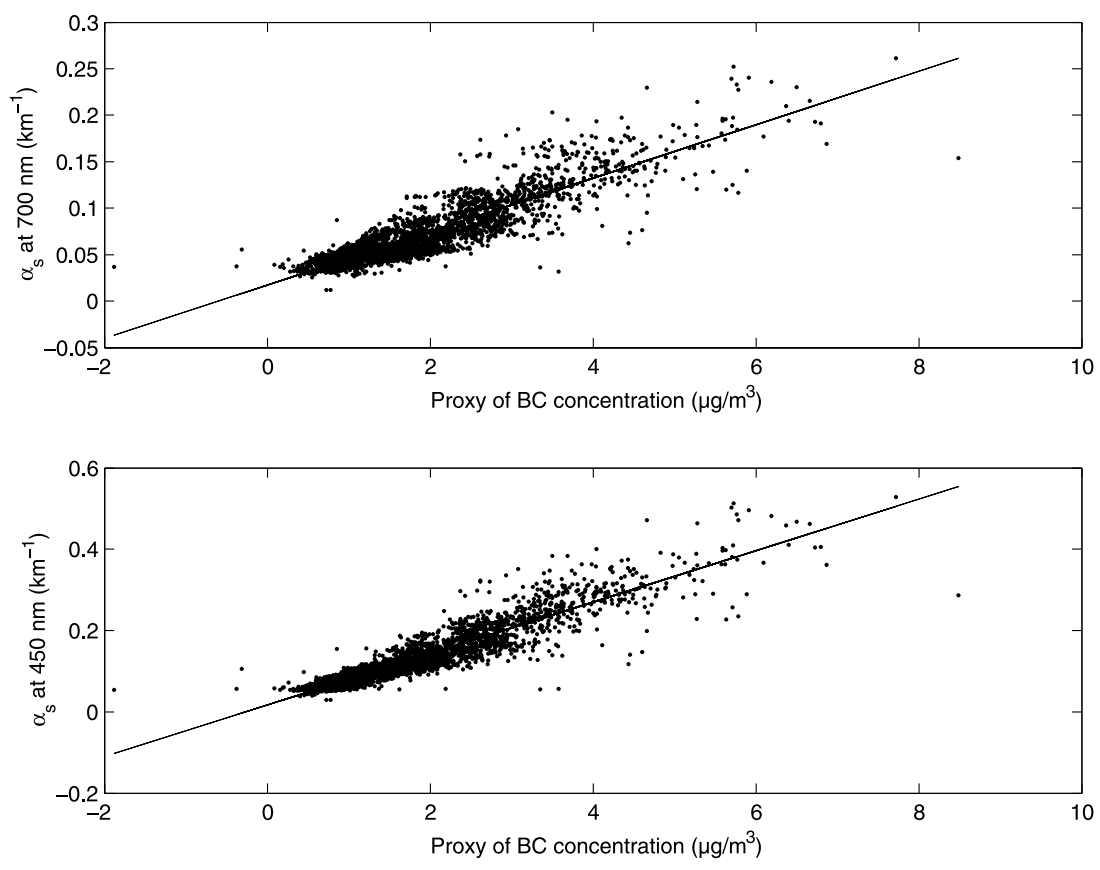

Figure 6. Proxy of the $B C$ (aethalometer measurement) as a function of the nephelometer-measured aerosol scattering coefficient $\left(\alpha_{s}\right)$ for both wavelengths, 700 (top) and $450 \mathrm{~nm}$ (bottom). 


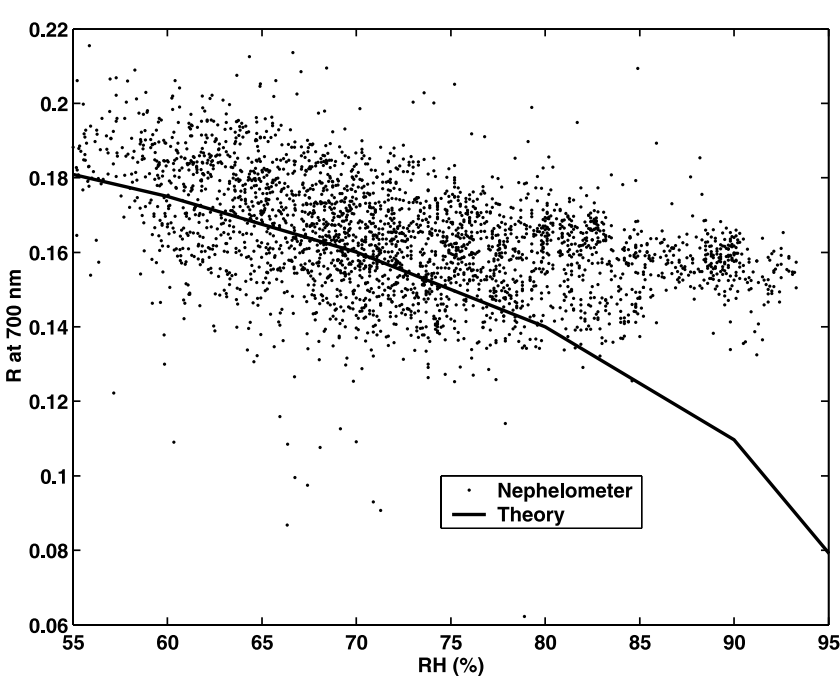

Figure 7. Backscatter-to-scattering ratio $(R)$ as a function of the $R H$ for both the nephelometer measurement and the theory.

Sun photometer data is used, it is possible to theoretically calculate $R$ using Hänel's [1976] laws. The comparison between theory and measurements shows that the modelderived values of $R$ are much more sensitive to $R H$ than measurements, which exhibit a weak negative trend. Once again, this shows that the $R H$ seems then to affect light scattering on a second order at the ground level as confirmed by the results of Cantrell et al. [2000, 2001] in the Maldives. They suggest that some components, presumably organic material, inhibit the hydrophilic properties of the aerosols. The sunlight scattering at the ground level can be traced by the $B C$.

[30] From the regression between $B C$ and $\alpha_{s}$ obtained for the period 10-26 March, it is possible to derive $\alpha_{s}$ from $B C$ for the entire lidar measurement. The scattering coefficient $\alpha_{B C}$ at the lidar wavelength of $523 \mathrm{~nm}$ is then derived using the Angström exponent in the visible spectrum of $\approx 1.5$ deduced from the nephelometer measurements (Figure 8).

[31] Due to the uncertainties in the overlap function close to the ground, $\alpha_{B C}$ cannot be used directly to constrain the inversion of the lidar profiles.

\subsubsection{A New Boundary Condition for the Inversion of the Lidar Measurements}

[32] Nevertheless, the inversion of the lidar measurements could be constrained if a relationship could be found between $\alpha_{B C}$ and the lidar extinction coefficients $\alpha_{e}(z)$ retrieved in the lower part of the profiles.

[33] The correlation coefficient between $\alpha_{e}(z)$ and $\alpha_{B C}$ has then been calculated over the whole daytime extinction lidar profiles as a function of the altitude to find another reference level close to the surface. Figure 9 gives the vertical profile of the correlation coefficient. The correlation coefficient peaks significantly at $110 \mathrm{~m}$ ASL $(90 \mathrm{~m}$ above ground level (AGL)) and quickly decreases above $200 \mathrm{~m}$ AGL. This highlights a significant vertical evolution of the aerosol properties as shown by Reus et al. [2001] following airborne measurements above the Indian Ocean. The correlation coefficient will be supposed to be the same at night- time and will then be considered hereafter as a boundary condition in the nighttime lidar inversion.

[34] After a first linear least squares fitting between daytime $\alpha_{e}(110 \mathrm{~m})$ and $\alpha_{B C}$, only the data within one standard deviation of the linear fit are kept. This constitutes a subensemble of about 470 points on which a second linear fitting is performed, leading to the relationship: $\alpha_{e B C}=0.6$ $\alpha_{B C}+0.2$ with an explained variance larger than $80 \% . \alpha_{e B C}$ will then represent the extinction coefficient at the reference altitude of $110 \mathrm{~m}$ ASL.

[35] The nighttime assessment of $\Phi_{p}$ is also made with an iterative procedure similar to the daytime procedure: the initial condition is the one retrieved for daytime $\left(0.028 \mathrm{sr}^{-1}\right)$ and the interval of likely values of $\Phi_{p}$ is always [0.005; $0.060] \mathrm{sr}^{-1}$ with an iterative step of $0.002 \mathrm{sr}^{-1}$. The daytime constraint is more accurate than that of nighttime because it is associated with a direct optical thickness measurement of low uncertainty. In nighttime, the convergence condition is relaxed and it becomes: $\left|\alpha_{e B C}-\alpha_{e}\right|<0.05 \mathrm{~km}^{-1}$. The value of $0.05 \mathrm{~km}^{-1}$ is the mean distance between $\alpha_{e B C}$ and the linear fitting.

[36] Figure 10 shows the histogram of the nighttime assessed values of $\Phi_{p}$, which is very narrow compared to the daytime one (Figure 4). This is mainly due to a better SNR on the upper boundary condition $S_{0}$. The statistic has been done with more than 1200 significant nighttime lidar profiles. More than $60 \%$ of these lidar profiles have permitted to retrieve a significant value of $\Phi_{p}$. On this subensemble, the mean value of $\Phi_{p}$ is then equal to $0.032 \mathrm{sr}^{-1}$ with a standard deviation of $0.006 \mathrm{sr}^{-1}$. It is noteworthy that about the same value is found for daytime and nighttime. The assumption on a conservative correlation coefficient between daytime and nighttime may be confirmed. There is no reason to think that the aerosol type significantly changes between daytime and nighttime.

[37] The nonconvergent profile inversions have been treated using the $\Phi_{p}$ mean value of $0.032 \mathrm{sr}^{-1}$. The histogram of $\tau_{L}$ is hence determined for nighttime and shown in Figure 11. The mean optical thickness at $523 \mathrm{~nm}$ is 0.76 with a standard deviation of 0.15 .

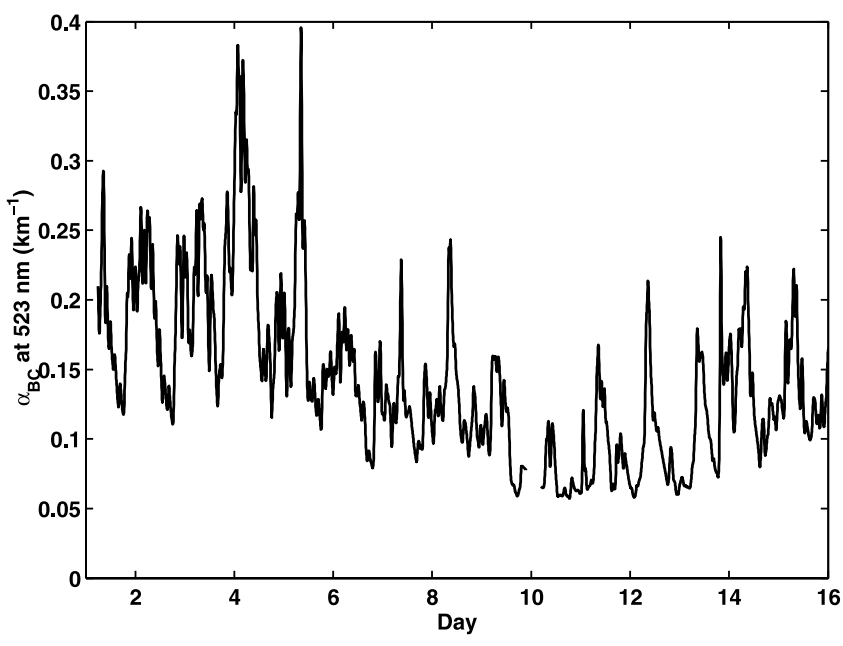

Figure 8. Temporal evolution of the aerosol scattering coefficient $\left(\alpha_{B C}\right)$ deduced from the statistical relationship between the $B C$ and the nephelometer scattering coefficient. 


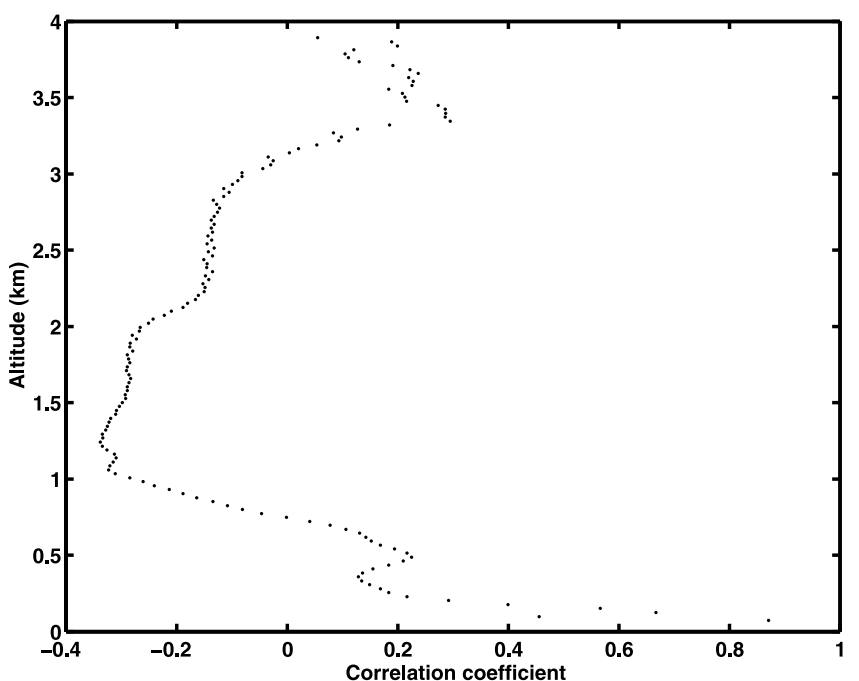

Figure 9. Vertical profile of the correlation coefficient between the lidar aerosol extinction coefficient from $110 \mathrm{~m}$ ASL and the assessed scattering coefficient at ground level $\left(\alpha_{B C}\right)$.

[38] The assessment of $\Phi_{p}$ has been also performed for the two daytime periods of 8 and 15 March when the Sun photometer-derived optical thickness is not available using the nighttime procedure. $\Phi_{p}$ has been found to be equal to $0.028 \mathrm{sr}^{-1}$ with a standard deviation of $0.003 \mathrm{sr}^{-1}$ on 80 significant lidar profiles. $\tau_{L}$ is sometime larger than 1 and the mean value is higher than the one for the other periods. These values could be associated with a residual cloud presence at the top of the monsoon layer. Note that Sun photometer measurements were not exploitable because of such a presence.

\section{Discussion of Uncertainties}

[39] The uncertainties on the aerosol extinction coefficient $\alpha_{e}$ are mainly due to the statistical fluctuation of the

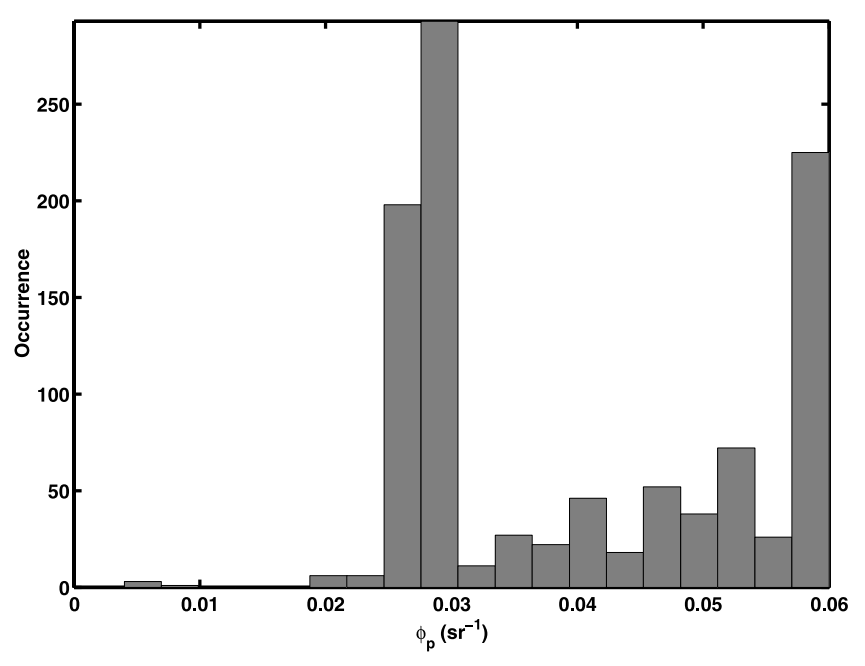

Figure 10. Histogram of the aerosol backscatter-toextinction ratio $\left(\Phi_{p}\right)$ assessed from the nighttime lidar measurement.

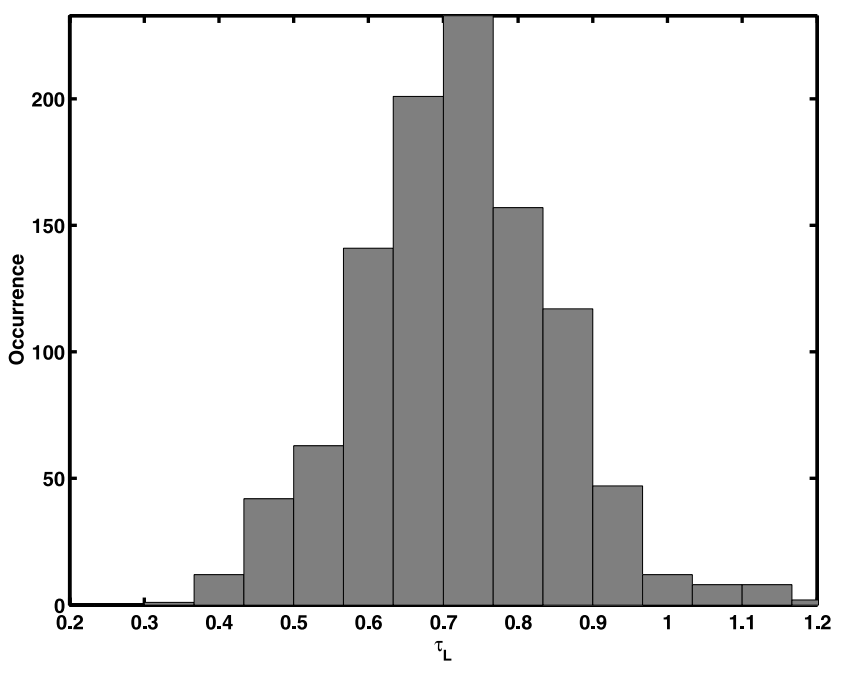

Figure 11. Histogram of the nighttime lidar-retrieved aerosol optical thickness at $523 \mathrm{~nm}\left(\tau_{L}\right)$.

lidar signal, the uncertainty on $\Phi_{p}$, the uncertainty on the reference signal $S_{0}$ and the uncertainty on the inverse of the overlap function $F$ (Figure 3 ). The resulting bias and standard deviations on both the lidar-retrieved extinction coefficient and the optical thickness have been assessed. Due to the importance of the error sources, the bias and the standard deviations have been calculated using a Monte Carlo procedure as in the work of Chazette et al. [2002]. They have been obtained from 2000 random realizations for each error source, which thus ensures a normal distribution around the mean value.

[40] Daytime and nighttime must be separately analyzed because both the procedure and the SNR are different. The uncertainty on the reference level has been calculated using the SNR at the altitude $z_{0}$, which is close to 4 in daytime whereas it is close to 6 in nighttime. The uncertainty on $1 / F$ has been associated with the one on the lidar signal. The molecular model has been considered as inducing a relative uncertainty of $5 \%$ on the molecular backscatter coefficient $\beta_{0}$ [Chazette et al., 1995]. The standard deviation on $\Phi_{p}$ is considered as being equal to previously determined values ( 0.010 and $0.006 \mathrm{sr}^{-1}$ in daytime and nighttime respectively).

[41] Figure 12 gives the mean extinction vertical profiles over the whole period and the overall standard deviations (in gray) of both daytime and nighttime. In the lower part of the profiles (under $0.5 \mathrm{~km}$ ) the uncertainty on the overlap function is the most important source of uncertainty. Nevertheless, it seems that the extinction coefficient increases significantly close to $90 \mathrm{~m}$ AGL. Local aerosol productions may explain such a phenomenon. The uncertainties due to the knowledge of the reference and $\Phi_{p}$ are of the same order. For both daytime and nighttime, a positive bias has been calculated: $\approx 25 \times 10^{-3}$ and $\approx 0.02 \mathrm{~km}^{-1}$ for nighttime and daytime respectively. They are mainly due to the nonlinear behavior of the solution as a function of $\Phi_{p}$.

[42] During daytime, the aerosol optical thickness is given by the Sun photometer with an absolute error less than 0.05 except on 8 and 15 March. During nighttime (daytime), the Monte Carlo procedure leads to a standard deviation on $\tau_{L}$ linked to $\Phi_{p}$ as equal to 0.07 (0.13), and the one linked to the signal noise is assessed as equal to 0.06 

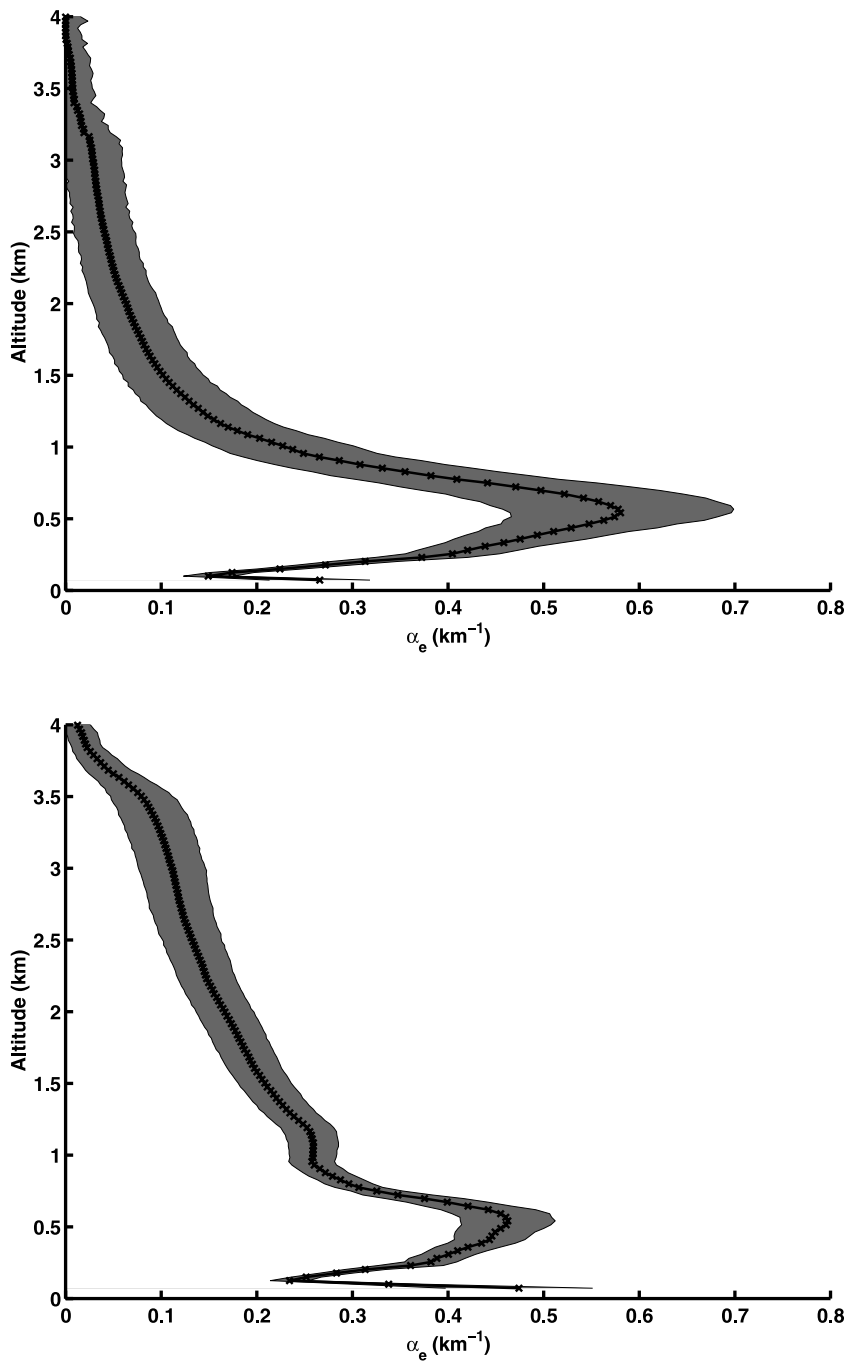

Figure 12. Typical mean vertical profile of the aerosol extinction coefficient $\left(\alpha_{e}\right)$ and its associated total standard deviation (in gray) for (a) daytime and (b) nighttime.

(0.09). The total uncertainty on $\tau_{L}$ is hence close to 0.1 (0.16) during nighttime (daytime) with a positive bias less than $0.1(0.05)$.

\section{Overall Results and Discussion}

\subsection{Aerosol Backscatter-to-Extinction Ratio}

[43] The daily mean values of $\Phi_{p}$ are given in Figure 13 with their associated daily standard deviations. A smaller variability is observed during nighttime. The spread of daytime values is mainly due to the signal noise. As already mentioned, both daytime and nighttime overall average are close to $0.03 \mathrm{sr}^{-1}$.

[44] As shown in Table 1, except for 1 March daytime where $\Phi_{p} \approx 0.015 \mathrm{sr}^{-1}$, the mean daytime values are larger than $0.023 \mathrm{sr}^{-1}$. The daytime values of $\Phi_{p}$ have also been calculated with a Mie code using the Sun photometerderived size distribution and complex refractive index found on the AERONET website [Holben et al., 1998] based on both Dubovik and King [2000] and Dubovik et al. [2000] methods. A value between 0.011 and $0.016 \mathrm{sr}^{-1}$ has been retrieved for 1 March, which is in good agreement with the previous result (Table 1). Larger values, between 0.017 and $0.023 \mathrm{sr}^{-1}$, are obtained between 2 and 15 March. They are generally lower than the lidar-derived values but in the majority of the cases, the agreement is obtained if the respective standard deviations are considered. The discrepancy may be due to the limited time periods for which the Sun photometer measurements are inverted to retrieve the aerosol size distribution and the complex refractive index. These periods correspond to sky radiance measurements performed in the morning and/or in the evening and only about 4 cases a day are available. The uncertainty on lidarderived values is however too large to detect short-term evolution of $\Phi_{p}$.

[45] The inversion of airborne lidar profiles constrained by Sun photometer data has also been used by Pelon et al. [2001] near Malé (Maldives, see Figure 1). It leads to smaller values of $\Phi_{p}$, between 0.010 and $0.013 \mathrm{sr}^{-1}$. Ansmann et al. [2000] found about the same values 16 days later from ground lidar data at Kaashidhoo. The differences between the Goa and Malé/Kaashidhoo measurements may be associated with a chemical evolution of the aerosol trapped inside the monsoon plume or with a difference in the air mass origins [Pelon et al., 2001]. Note also, that the value of $\Phi_{p}$ deduced from the monomodal aerosol model used to inverse the Meteosat data over the Indian Ocean by Léon et al. [2001] is about the same $\left(0.016 \mathrm{sr}^{-1}\right)$ as the one retrieved near Malé.

[46] Nevertheless, the ground in situ measurements have shown that the aerosol model is mainly trimodal [i.e., Satheesh et al., 1999; Alfaro et al., 2001] with a significant contribution to the extinction due the first two modes. A bimodal structure has been also retrieved by Moorthy et al. [2001] over the Arabian sea and by Eck et al. [2001] over the Maldives from the island of Kaashidhoo. At the coastal site of Goa, the optical efficiency modes determined by Alfaro et al. [2001] are defined by modal radii of $0.049 \mu \mathrm{m}$ and $0.46 \mu \mathrm{m}$, and geometric standard deviations of 1.7 and

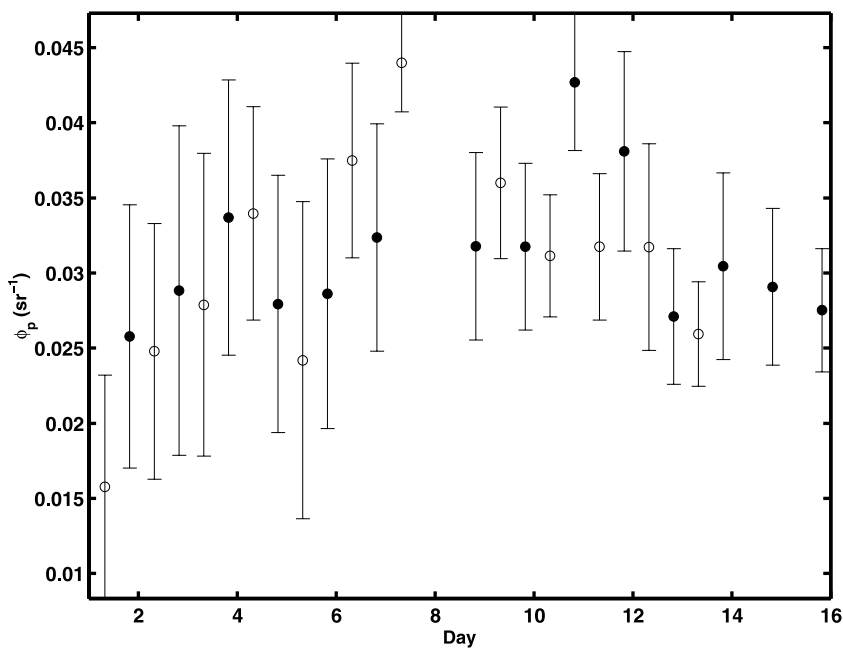

Figure 13. Temporal evolutions between 1 and 15 March of both daytime (empty circle) and nighttime (filled circle) daily mean $\Phi_{p}$ for the entire lidar measurement period. The bars represent the standard deviation on the daily temporal variability of $\Phi_{p}$. 
Table 1. Mean Values of the Aerosol Backscatter-to-Extinction Ratio $\left(\Phi_{p}\right)$ Deduced From the Measurements Performed in the Goa and Malé Areas During Daytime (Light) and Nighttime (Bold)

\begin{tabular}{lccc}
\hline \multicolumn{1}{c}{ Authors } & Location & IFP date (March 1999) & $\Phi_{p}\left(\mathrm{sr}^{-1}\right)$ \\
\hline This paper & Goa & 1 & $0.015 \pm 0.01$ \\
& & $2-15$ & $0.028 \pm 0.01$ \\
AERONET & Goa & 1 & $\mathbf{0 . 0 3 2} \pm \mathbf{0 . 0 0 6}$ \\
& & $2-15$ & $0.011-0.016$ \\
Ansmann et al. $[2000]$ & Malé & 25 & $0.017-0.023$ \\
Pelon et al. $[2001]$ & Malé (lidar) & $7-9$ & $\mathbf{0 . 0 1 0 - 0 . 0 1 5} \mathbf{( 0 . 5}-\mathbf{4} \mathbf{~ k m )}$ \\
& Malé (AERONET) & 10 & $0.010-0.013$ \\
Sicard et al. [2002] & Goa & 11 & $0.012-0.015$ \\
& & $1-15$ & $\mathbf{0 . 0 3 2} \mathbf{( 0 . 5}-\mathbf{1 . 5} \mathbf{~ k m})$ \\
Léon et al. $[2001]$ & Malé/Goa (Meteosat) & & $0.038(0.7-2 \mathbf{k m})$ \\
\hline
\end{tabular}

1.2. The first mode is constituted of carbonaceous core coated with non absorbent material and represents $99.95 \%$ of the total aerosol number. The second mode is constituted of non-sea-salt sulfate, noncoated black carbon, mineral dust, sea salt and other water-soluble compounds. Such aerosols are mainly a product from the use of fossils fuels, some biomass fuels and various industrial processes as mentioned by Novakov et al. [2000]. Hence, with the use of the median complex refractive index available for Goa, thanks to the inversion performed in the frame of the AERONET network (1.6-0.011), an other assessment of $\Phi_{p}$ is possible, which leads to a value close to $0.03 \pm 0.005$ $\mathrm{sr}^{-1}$. Such a value is in good agreement with the present results but supposes that the aerosol size distribution did not change in the atmospheric column. Note that a bimodal structure could also be observed on the Sun photometerretrieved size distribution.

[47] $\Phi_{p}$ could be different between the surface layer and both the mixing layer and the free troposphere as shown by Ansmann et al. [2000]. Sicard et al. [2002] report values of 0.032 and $0.015 \mathrm{sr}^{-1}$ for the layers $0.5-1.5$ and $2-3 \mathrm{~km}$, respectively, over Goa on 10 March (Table 1). These values are retrieved without hypotheses on the aerosol model because a multiangular inversion approach has been conducted on the lidar data using specific measurement scenarios with zenithal scanning. Such variability of $\Phi_{p}$ with the altitude may be due to the influence of different air mass origins. Note also that the optical ground measurements appear to be little correlated to the lidar extinction coefficient above $110 \mathrm{~m}$ ASL. The weak humidity effect on the aerosols observed at the surface may not be true at higher altitude. However, this previous hypothesis cannot be verified with a sufficient reliability because not enough radiosounding are available near Goa. The $R H$ seems to be smaller in altitude than close to the surface, which could explain the weaker values of $\Phi_{p}$ found above $2 \mathrm{~km}$ by Sicard et al. [2002].

\subsection{Aerosol Optical Thickness and Extinction Profile Diurnal Evolution}

[48] Figure 14 gives the temporal evolution of both the aerosol extinction profile and its associated optical thickness at Goa between 1 and 15 March. The Sun photometerderived optical thicknesses are also given.

[49] The mean optical thickness at $523 \mathrm{~nm}$ calculated during nighttime $(0.76 \pm 0.15$ with an absolute uncertainty of 0.1 ) has been found to be significantly larger than the daytime one $(0.55 \pm 0.09$ with an absolute uncertainty of 0.05 and 0.16 for Sun photometer and lidar data respectively). During daytime, the good coherence between the optical thickness derived from Sun photometer and lidar data is due to the use of Sun photometer data as an input boundary condition for the inversion of the lidar data. Nevertheless, the daytime optical thickness retrieved for 15 March seems to be coherent with the other one. The optical thickness is mainly the sum of the contribution of two aerosol layers. Indeed, the lidar vertical profiles reveal a double aerosol layer that is more marked during nighttime as shown in Figure 12. Similar observations were done at the Kaashidhoo Climate Observatory (KCO, $4.96^{\circ} \mathrm{N}$, $73.46^{\circ} \mathrm{E}$ ) during the first field phase of INDOEX (from 20 February to 31 March 1998) [Satheesh et al., 1999]. Over the Maldives (Hulule island, $4.1^{\circ} \mathrm{N} 73.3^{\circ} \mathrm{E}$ ) Müller et al. [2001] showed also such a vertical structure during nighttime with values of the extinction coefficient of the same order of magnitude.

[50] A dense aerosol layer of about $0.7 \pm 0.1 \mathrm{~km}$ thick can be observed over the entire measurement period. The mean

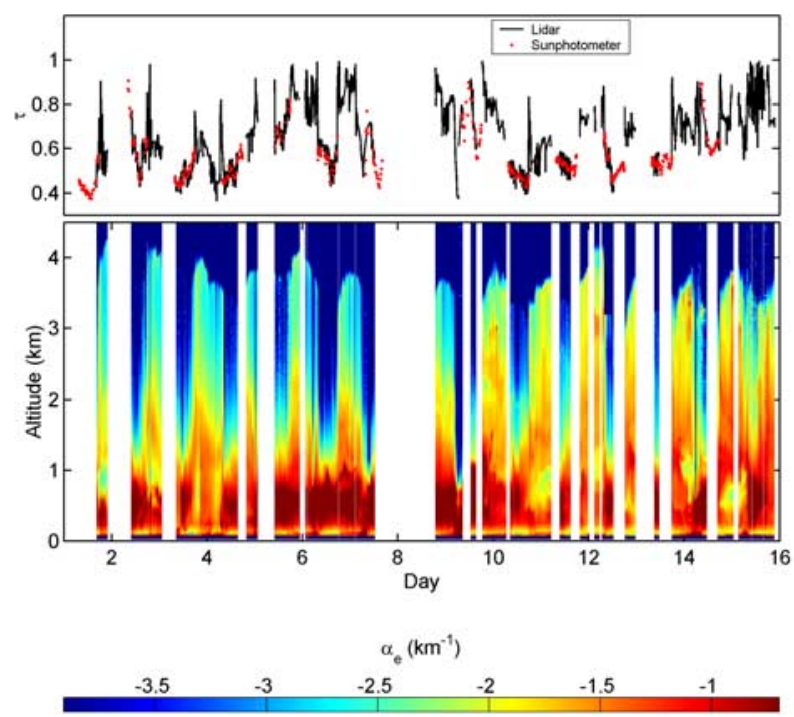

Figure 14. Temporal evolution between 1 and 15 March of both the lidar-retrieved aerosol extinction vertical profile $\left(\alpha_{e}\right.$, bottom) and the total aerosol optical thickness ( $\tau$, top) deduced from lidar and Sun photometer measurements. 


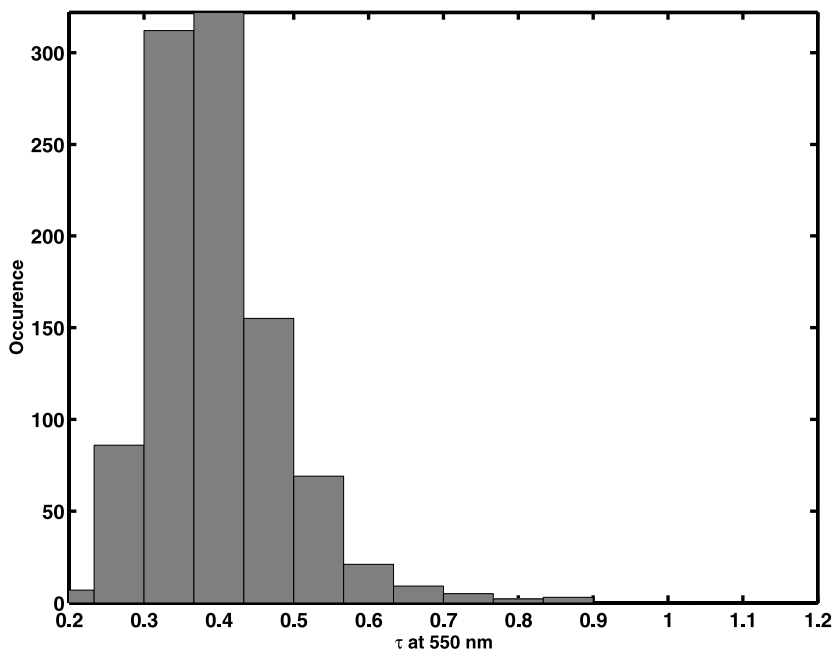

Figure 15. Histogram of the Meteosat-derived aerosol optical thickness at $550 \mathrm{~nm}(\tau)$ for the geographic zone of $72-75^{\circ} \mathrm{E}$ and $14-17^{\circ} \mathrm{N}$ near the coastal instrument site of Goa.

optical thickness between 0.11 and $0.7 \mathrm{~km} \mathrm{ASL}$ is of about $0.3 \pm 0.09$ during daytime and $0.27 \pm 0.13$ during nighttime. This layer likely corresponds to the planetary boundary layer (PBL) and its optical thickness seems to remain constant between daytime and nighttime. On the contrary, the surface scattering coefficient is different between nighttime and daytime (Figure 8). The surface extinction coefficient during nighttime is generally more than $30-40 \%$ larger than during daytime. The difference between daytime and nighttime may be a consequence of variability in the strength of local source emissions. The second layer thickness varied significantly between daytime and nighttime. The optical thickness between 0.7 and $4 \mathrm{~km}$ ASL in nighttime $(0.49 \pm 0.14)$ is bigger than in daytime $(0.25 \pm 0.07)$. Such a difference could be due to local/regional dynamical

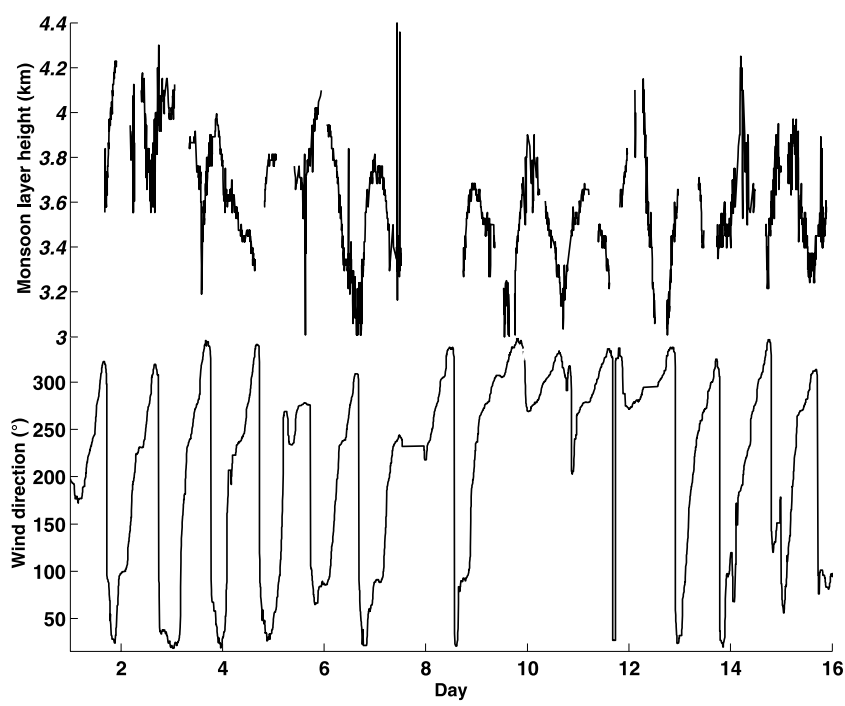

Figure 16. Temporal evolution between 1 and 15 March 1999 of the monsoon layer top and the wind direction at $6 \mathrm{~m}$ AGL.
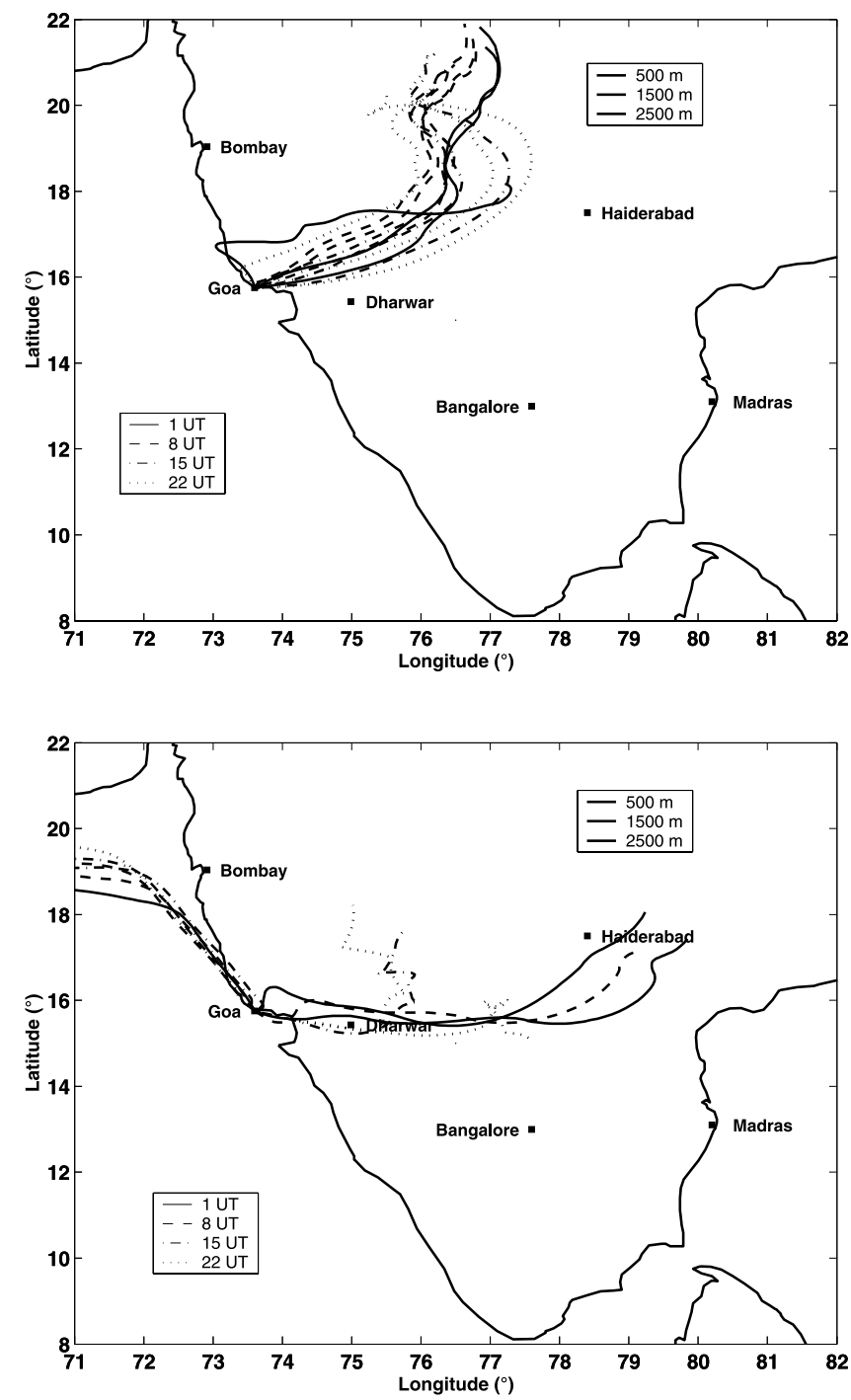

Figure 17. Backtrajectories for two 3 day periods ending over Goa on (a) 5 and (b) 10 March 1999 (courtesy of NOAA Air Resources Laboratory http://www.arl.noaa.gov).

processes. The more probable process may be the sea breeze cycle described by Léon et al. [2001]. The standard deviation obtained during nighttime $(0.14)$ is more important than the one obtained during daytime (0.07), this may be due to the presence of some semitransparent clouds at the top of the monsoon layer $(\approx 3.5-4 \mathrm{~km}$ ASL).

[51] The weaker aerosol optical thicknesses observed during daytime above the PBL may be due to an air mass mixing with cleaner air coming from the Indian Ocean. To highlight the efficiency of the mixing effect, Figure 15 gives the histogram of the Meteosat derived optical thickness $\tau$ at $550 \mathrm{~nm}$ from 1 to 15 March. The geographic zone of $72-$ $75^{\circ} \mathrm{E}$ and $14-17^{\circ} \mathrm{N}$ close to the coastal site of Goa has been considered. The mean optical thickness is $\approx 0.40 \pm 0.10$. It is less than the lidar-retrieved values at the station of Goa. This may show the efficiency of the dilution of continental aerosols during their advection above the Indian Ocean, which has been highlighted by Moorthy et al. [2001].

[52] The monsoon layer top as determined from the lidar profiles [Chazette et al., 2002] is also directly linked with 
the optical thickness variability over Goa. Figure 16 shows the temporal evolution of both the monsoon layer top and the wind direction at $6 \mathrm{~m}$ AGL on the instrumental site. The wind direction follows the sea breeze cycle, as does the top of the monsoon layer. The sea breeze is associated with a lower monsoon layer $(\approx 3-3.5 \mathrm{~km}$ ASL for a wind direction from $\approx 300^{\circ}$ to $\left.320^{\circ}\right)$ than the continental breeze $(\approx 3.7-4.3$ $\mathrm{km}$ ASL for a wind direction from $\approx 40^{\circ}$ to $100^{\circ}$ ). No continental breeze seems to be present between 10 and 12 March with a wind direction of $\approx 250^{\circ}$. The Mormugao bay may influence the local wind direction when the wind is mainly from south.

[53] Between 1 and 8 March, the synoptic air masses were from continental origin on the entire atmospheric column as illustrated by the backtrajectories computed on 3 days and ending over Goa on 5 March (Figure 17a). During the second period of lidar measurements (between 9 and 15 March) illustrated in Figure 17b for 10 March, the synoptic circulation changed at low altitude. This difference does not seem to significantly modify the diurnal evolution of the total aerosol optical thickness over Goa. The influence of the air mass origin on the aerosol load may be more easily understood during the second period at the synoptic scale. Indeed, a change in the synoptic circulation mainly occurs for levels below $1500 \mathrm{~m}$ ASL where the air masses came mainly from the Bombay coast. The level of $1500 \mathrm{~m}$ ASL corresponds to the biggest contributor to the total optical thickness and the air mass origins are different for this level between daytime and nighttime. The nighttime is associated with air masses from the continent whereas they are from Bombay coast during daytime. Hence, it may be possible for the polluted air masses to be mixed with oceanic air masses during daytime in the second period, but when the optical thickness is compared with the one of the first period, this effect does not seem significant.

[54] Nevertheless, the more probable and efficient process, which can explain the diurnal cycle of the optical thickness, is the local sea/land breeze recurrence. This cycle may be enhanced by the diurnal aerosol production linked to the local sources.

\section{Conclusion}

[55] Lidar observations were performed on the instrumental site of Goa from 1 to 15 March 1999. The vertical profiles of the extinction coefficient have been calculated. The Sun photometer-derived optical thickness has been used as a constraint to assess the mean value of the backscatter-to-extinction ratio $\left(\Phi_{p}\right)$ during daytime. The value of $\Phi_{p}$ assessed at nighttime used the statistical relationship between the ground nephelometer-derived scattering coefficient and the ground aethalometer-derived $B C$. Such a possibility has been offered thanks to the weak influence of the $R H$. A mean value of $\Phi_{p}$ close to $0.03 \pm 0.010 \mathrm{sr}^{-1}$ has been retrieved both for nighttime and daytime in agreement with the value assessed from ground in situ measurements. Such a value is about $40 \%$ larger than those determined on the Goa site from Sun photometer measurements. It is significantly larger than those retrieved close to the Malé area, which are $\approx 0.012 \mathrm{sr}^{-1}$. This difference could most probably be explained by the fact that air mass origins may be different between Malé and Goa [i.e., Pelon et al., 2002]. Multidirectional lidar measurements performed over Goa show that $\Phi_{p}$ may be variable according to the altitude [Sicard et al., 2002] but they give values of $\Phi_{p}$ in agreement with the mean value here retrieved.

[56] The use of MPL measurements allows the retrieval of the aerosol optical thickness during nighttime. The mean optical thickness retrieved from lidar measurements performed at $523 \mathrm{~nm}$ during nighttime $(0.76 \pm 0.15)$ has been found to be larger than the daytime one $(0.55 \pm 0.09)$. It seems mainly driven by the temporal evolution of the monsoon layer associated with the sea breeze circulation.

[57] The analysis of the vertical profiles of the extinction coefficient has highlighted the small correlation between surface measurements and the atmospheric column. Synoptic circulation and mainly the local sea breeze effect could explain this weak correlation.

[58] Acknowledgments. The Programme National de Chimie AtmosphÕrique (PNCA) funded this work. The author would like to thank the French science team involved in the Goa experimental site during the IFP of INDOEX. F. Dulac, P. Couvert, and E. Devlin are gratefully acknowledged for reviewing this paper. This is LSCE contribution 0795.

\section{References}

Alfaro, S. C., L. Gomes, A. Gaudichet, J. L. Rajot, J. F. Léon, H. Cachier, P. Chazette, and F. Dulac, Modeling of aerosol optical properties at an Indian coastal site during the 1999 INDOEX field phase, J. Aerosol Sci., 32(suppl. 1), S423-S424, 2001

Angström, A., The parameters of atmospheric turbidity, Tellus, 16, 64-75, 1964.

Ansmann, A., D. A. U. Wandinger, K. Franke, D. Müller, F. Wagner, and J. Heintzenberg, Vertical profiling of the Indian aerosol plume with six-wavelength lidar during INDOEX: A first case study, Geophys. Res. Lett., 27, 963-966, 2000.

Bodhaine, B. A., Aerosol absorption measurements at Barrow, Mauna Loa and the South Pole, J. Geophys. Res., 100, 8967-8975, 1995.

Bodhaine, B. A., N. C. Ahlquist, and R. C. Schnell, Three-wavelength nephelometer suitable for aircraft measurements of background aerosol scattering coefficient, Atmos. Environ., 10, 2268-2276, 1991.

Cantrell, W., G. Shaw, C. Leck, L. Granat, and H. Cachier, Relationships between cloud condensation nuclei spectra and aerosol particles on a south-north transect of the Indian Ocean, J. Geophys. Res., 105, $15,313-15,320,2000$

Cantrell, W., G. Shaw, G. R. Cass, Z. Chowdhury, L. S. Hughes, K. A. Prather, S. A. Guazzotti, and K. R. Coffee, Closure between aerosol particles and cloud condensation nuclei at Kaashidhoo climate observatory, J. Geophys. Res., 106, 28,711-28,718, 2001.

Charlson, R. J., S. E. Schwartz, J. M. Hales, R. D. Cess, J. J. A. Coakley, J. E. Hansen, and D. J. Hofmann, Climate forcing by anthropogenic aerosols, Science, 255, 423-430, 1992

Charlson, R. J., T. L. Anderson, and H. Rodhe, Direct climate forcing by anthropogenic aerosols: Quantifying the link between atmospheric sulfate and radiation, Contrib. Atmos. Phys., 72, 79-74, 1999

Chazette, P., C. David, J. Lefrère, S. Godin, J. Pelon, and G. Mégie, Comparative lidar study of the optical, geometrical, and dynamical properties of stratospheric post-volcanic aerosols, following the eruptions of El Chichon and Mount Pinatubo, J. Geophys. Res., 100, 23,195-23,207, 1995.

Chazette, P., J.-F. Leon, H. Cachier, F. Dulac, S. C. Alfaro, L. Gomes, A. Gaudichet, J.-L. Rajot, J. G. Won, and S. C. Yoon, Consistence between lidar and ground-based measurements in the frame of INDOEX intensive field phase, in Proc. 20th Int. Lidar Radar Conf., edited by J. Pelon and A. Dabas, 2000.

Chazette, P., J. Pelon, C. Moulin, F. Dulac, I. Carrasco, W. Guelle, P. Bousquet, and P. H. Flamant, Airborne lidar and Meteosat synergy to characterize a Saharan dust plume over the Azores during SOFIA/ASTEX, Atmos. Environ., 35, 4297-4304, 2001.

Chazette, P., J. Pelon, and G. Mégie, Determination of structural parameters of atmospheric scattering layer using spaceborne backscatter lidar, Appl. Opt., in press, 2002

Dickerson, R. R., S. Kondragunta, G. Stenchikov, K. L. Civerolo, B. G. Doddridge, and B. N. Holben, The impact of aerosols on solar ultraviolet radiation and photochemical smog, Science, 278, 827-830, 1997. 
Dubovik, O., and M. D. King, A flexible inversion algorithm for retrieval of aerosol optical properties from sun and sky radiance measurements, J. Geophys. Res., 105, 20,673-20,696, 2000.

Dubovik, O., A. Smirnov, B. N. Holben, M. D. King, Y. J. Kaufman, T. F. Eck, and I. Slutsker, Accuracy assessments of aerosol optical properties retrieved from AERONET sun and sky radiance measurements, J. Geophys. Res., 105, 9791-9806, 2000.

Eck, F., B. N. Holben, O. Dubovik, A. Smirnov, I. Slutsker, J. M. Lobert, and V. Ramanathan, Column-integrated aerosol properties over the Maldives during the northeast monsoon for 1998-2000, J. Geophys. Res., $106,28,555-28,566,2001$.

Fernald, F. G., B. M. Herman, and J. A. Reagan, Determination of aerosol height distribution by lidar, J. Appl. Meteorol., 11, 482-489, 1972.

Flamant, C., V. Trouillet, P. Chazette, and J. Pelon, Wind speed dependence of the atmospheric boundary layer optical properties and ocean surface reflectance as observed by airborne backscatter lidar, J. Geophys. Res. 103, 25,137-25,158, 1998

Flamant, C., et al., Airborne lidar measurements of aerosol spatial distribution and optical properties over the Atlantic Ocean during an European pollution outbreak of ACE-2, Tellus, 52B, 662-667, 2000

Fouquart, Y., B. Bonnel, M. Chaoui Roquai, R. Santer, and A. Cerf, Observations of Saharan aerosols: Results of ECLATS field experiment, part I, Optical thicknesses and aerosol size distribution, J. Clim. Appl. Meteorol., 26, 28-37, 1987.

Hamonou, E., P. Chazette, D. Balis, F. Dulac, X. Schneider, E. Galani, G. Ancellet, and A. Papayannis, Characterisation of the vertical structure of Saharan dust export to the Mediterranean basin, J. Geophys. Res., 104, 22,257-22,270, 1999.

Hänel, G., The properties of atmospheric aerosol particles as functions of the relative humidity at thermodynamic equilibrium with the surrounding moist air, Adv. Geophys., 19, 73-188, 1976.

Hansen, A. D. A., and T. Novakov, Real time measurements of aerosol black carbon during the carbonaceous species methods comparison study, Aerosol Sci. Technol., 12, 194-199, 1990.

Holben, B. N., et al., AERONET: A federated instrument network and data archive for aerosol characterisation, Remote Sens. Environ., 66, 1-16, 1998.

Klett, J. D., Stable analytical inversion solution for processing lidar returns, Appl. Opt., 20, 211-220, 1981.

Klett, J. D., Lidar inversion with variable backscatter/extinction ratios, Appl. Opt., 24, 1638-1643, 1985.

Kohl, R. H., Discussion of the interpretation problem encountered in singlewavelength lidar transmissionmeters, J. Appl. Meteorol., 17, 1034-1038, 1978.

Lelieved, J., et al., The Indian Ocean Experiment: Widespread air pollution from south and Southeast Asia, Science, 291, 1031-1036, 2001.

Léon, J. F., et al., Large scale advection of continental aerosols during INDOEX, J. Geophys. Res., 106, 28,427-28,440, 2001

Marchand, P., and L. Marmet, Binomial smoothing filter: A way to avoid some pitfalls of less-squares polynomial smoothing, Rev. Sci. Instrum. 54, 1034-1041, 1983.

Measures, R. M., Laser Remote Sensing, Wiley-Interscience, New York, 1984.
Moorthy, K. K., A. Saha, B. S. N. Prasad, K. Niranjan, D. Jhurry, and P. S. Pillai, Aerosol optical depths over peninsular India and adjoining oceans during the INDOEX campaign: Spatial, temporal, and spectral characteristics, J. Geophys. Res., 106, 28,539-28,554, 2001.

Müller, D., K. Franke, F. Wagner, D. Althausen, A. Ansmann, and J. Heintzenberg, Vertical profiling of optical and physical particle properties over the tropical Indian Ocean with six-wavelength lidar, 2, Case studies, J. Geophys. Res., 106, 28,577-28,595, 2001.

Novakov, T., M. O. Andreae, R. Gabriel, T. W. Kirchstetter, O. L. MayolBracero, and V. Ramanathan, Origin of carbonaceous aerosols over the tropical Indian Ocean: Biomass burning or fossil fuels, Geophys. Res. Lett., 27, 4061-4064, 2000.

Pelon, J., P. Chazette, C. Flamant, J. F. Léon, D. Tanré, M. Sicard, and S. K. Satheesh, Characterization of aerosol spatial distribution and optical properties over the Indian Ocean from airborne lidar and radiometry during INDOEX'99, J. Geophys. Res., 107, 10.1029/2001JD000402, in press, 2001

Ramanathan, V., et al., Indian Ocean Experiment (INDOEX) White Paper, La Jolla, Calif. 92093-0239, USA, 1995.

Ramanathan, V., et al., The Indian Ocean Experiment: An integrated assessment of the climate forcing and effects of the Great Indo-Asian haze, J. Geophys. Res., 106, 28,371-28,398, 2001.

Rasch, P. J., W. D. Collins, and B. E. Beaton, Understanding the Indian Ocean Experiment INDOEX aerosol distributions with an aerosol assimilation, J. Geophys. Res., 106, 7337-7355, 2001.

Reus, M., R. Krejci, J. Williams, H. Fischer, R. Scheele, and J. Ström, Vertical and horizontal distributions of the aerosol number concentration and size distribution over the northern Indian Ocean, J. Geophys. Res., $106,28,629-28,641,2001$.

Satheesh, S. K., V. Ramanathan, X. Li-Jones, J. M. Lobert, I. A. Podgorny, J. M. Prospero, B. N. Holben, and N. G. Loeb, A model for the natural and anthropogenic aerosols over the tropical Indian Ocean derived from Indian Ocean Experiment data, J. Geophys. Res., 104, 27,421-27,440, 1999.

Sicard, M., P. Chazette, J. Pelon, J. G. Won, and S. C. Yoon, Variational method for the retrieval of the optical thickness and the backscatter coefficient from multiangle lidar profiles, Appl. Opt., 41, 493-502, 2002.

Spinhirne, J. D., Micro pulse lidar, IEEE Trans. Geosci. Remote Sens., 31, $48-55,1993$.

Spinhirne, J. D., J. Rall, and V. S. Scott, Compact eye-safe lidar systems, Rev. Laser Eng., 23, 26-32, 1985.

Tanré, D., C. Devaux, M. Herman, R. Santer, and Y. Gac, Radiative properties of desert aerosols by optical ground-based measurements at solar wavelengths, J. Geophys. Res., 93, 14,223-14,231, 1988.

Welton, E. J., et al., Ground-based lidar measurements of aerosols during ACE-2: Instrument description, results, and comparisons with other ground-based and airborne measurements, Tellus, 52B, 636-651, 2000.

P. Chazette, Laboratoire des Sciences du Climat et de 1'Environnement, UMR 1572 CEA-CNRS, F-91191, Gif-sur-Yvette, France. 